\title{
Ileocaecal Tuberculosis in A Nigerian Child: A Case Report
}

\section{Oloyede IP ${ }^{1 *}$, Dixon-Umo OT ${ }^{\mathbf{1}}$, Akpanudo EI ${ }^{2}$, David UD ${ }^{3}$ and Etuk J-F ${ }^{4}$}

${ }^{1}$ Senior Lecturer and Honorary Consultant, Department of Paediatrics, University of Uyo and University of Uyo Teaching Hospital, Nigeria

${ }^{2}$ Senior Lecturer and Honorary Consultant, Department of Paediatric Surgery, University of Uyo and University of Uyo Teaching Hospital, Nigeria

${ }^{3}$ Senior Registrar, Department of Paediatrics, University of Uyo Teaching Hospital, Nigeria

${ }^{4}$ Registrar, Department of Paediatrics, University of Uyo teaching Hospital, Nigeria

*Corresponding Author: IP Oloyede, Senior Lecturer and Honorary Consultant, Department

of Paediatrics, University of Uyo and University of Uyo Teaching Hospital, Nigeria.
Received: February 08, 2020

Published: February 28, 2020

(C) All rights are reserved by Oloyede IP., et al.

DOI: $10.31080 /$ ASPE.2020.03.0228

\section{Abstract}

Childhood Tuberculosis is a public health emergency in Nigeria. Abdominal tuberculosis (TB) is one of the commonest forms of extrapulmonary TB with nonspecific and protean clinical manifestations. We present a 5 year old girl with fever of two weeks, abdominal pain and swelling of three days duration and vomiting of two days duration. Other symptoms were anorexia, generalised body weakness and weight loss. Her significant physical findings were, moderate pallor, underweight, submandibular lymphadenopathy, abdominal distension, doughy abdomen and a tender tubular mass extending from the right lumbar to right iliac region. Her significant investigation results were a manteoux of $18 \mathrm{~mm}$, thickened ascending colon on abdominopelvic ultrasound scan and a histologic picture of caseous granuloma from a mesenteric lymphnode biopsy. Exploratory laparotomy revealed multiple caseation on the distal ileum, caecum and adjoining mesentery with a partially occluded caecal and ileal lumen and multiple mesenteric lymph node enlargement with a viable gut. A diagnosis of partial intestinal obstruction secondary to ileocaecal TB was made and she was managed with short course anti-tuberculous medication for a total of six months and had a good response.

In conclusion abdominal TB is still seen in Nigerian children. A high index of suspicion is essential for its' diagnosis. Anti-tuberculous medication is still the treatment of choice and surgery should be reserved for diagnosis and treatment of complications.

Keywords: Abdominal; Ileocecal; Tuberculosis; Children; Nigeria

\section{Introduction}

Childhood tuberculosis (TB) is of great public health importance in Nigeria [1]. Tuberculosis in children is a sentinel event, as it is usually a pointer to adult TB in the community. Tuberculosis can be described as a great simulator as it has a myriad of manifestations. Tuberculosis can affect virtually every body system [2]. Abdominal Tuberculosis is usually of three forms: TB enteritis, TB peritonitis and TB mesenteric adenitis [3,4]. A hospital study in Nigeria showed that abdominal TB accounted for $13 \%$ of all forms tuberculosis [5]. Indian studies have reported a prevalence rate of $0.8-3.6 \%$ for abdominal TB in hospitalised children [6-8]. The mode of transmission for Gastrointestinal (GIT) TB could be from spread of infection from pulmonary TB, swallowing of coughed up TB infected phlegm or by ingestion of unpasteurised milk or poorly cooked beef infected with Mycobacterium Bovis [4,9] in addition, reactivation of a latent focus, rupture of a mesenteric lymph node or contiguous spread from adjacent organs could also account for peritoneal infection [10]. Abdominal Tuberculosis is an uncommon cause of acute abdomen in children as most reports of abdominal TB presenting as acute abdomen have been on adults thus making our case an atypical one $[11,12]$. An Indian review showed that undiagnosed abdominal TB causes only about $10 \%$ of acute abdomen which requires emergency surgery [11]. One of the commonest mode of presentation of Abdominal TB is either as a partial or complete intestinal obstruction. It is impossible to differentiate Intestinal obstruction caused by TB from other causes of intestinal obstruction by clinical examination and radiologic investigations. The diagnosis is usually made at surgery and confirmed by histological and microbiological examination of biopsy specimens [13]. The commonest sites of bowel involvement are usually ileocaecal, ileum and ascending colon. Duodenal and appendicular lesions could also be seen [6]. It is imperative that the diagnosis be made 
early in order to initiate the appropriate anti- TB medications and prevent complications, like intestinal perforation.

We therefore present a case of ileocaecal TB that presented as a case of acute intestinal obstruction to the emergency room of the children emergency unit of the department of paediatrics, University of Uyo Teaching hospital (UUTH), Nigeria.

\section{Case Report}

MII is a five year old girl who presented via the children emergency unit with complaints of Fever of two weeks duration, abdominal pain and swelling of three days duration and vomiting of two days duration. The fever was low-grade, continuous and temporarily relieved by paracetamol. The abdominal pain was insidious in onset, located around the umbilicus and severe enough to disturb child's sleep. There was no known aggravating or relieving factor. There was an associated generalised abdominal swelling with no change in bowel habit. MII developed non-projectile, non- bloody and non- bilious vomiting consisting of recently ingested food two days prior to presentation in the emergency room. She had two to three episodes of vomiting per day with an estimated volume of 10 - 20 mls vomitus per episode. Other associated symptoms were abdominal distension, abdominal pain, anorexia and generalised body weakness. There was no cough, or night sweats, but there was appreciable weight loss. She was given a home alcohol based herbal remedy as rectal enema. Prior to presentation at UUTH, she was also given buscopan, metronidazole and amoxicillin purchased from a patent medicine dealer. With no improvement in symptoms she was taken to a peripheral hospital where she was treated with oral Augmentin and multivitamins. With persistence of symptoms she presented in our emergency unit for proper management.

MII's past medical history, perinatal and neonatal histories was uneventful. She was predominantly breastfed for the first four months of life, mixed feeding was given for four to seven months, thereafter mixed cereals was introduced and she was commenced on family diet at one year of age. Her pre-morbid dietary history was good and she was fed three to four times a day. She had completed her early childhood immunisation according to the $\mathrm{Ni}$ gerian program of immunization (NPI) schedule, though no BCG scar was seen on her left deltoid. MII is a primary one pupil, doing relatively well in school (11th position out of 21 pupils). MII is the 5th child in a monogamous setting who was born and had lived in Cameroon until three months prior to presentation. Her mother is a petty trader with secondary level of education, while her father is a junior staff of a plastic company with secondary level of education. She belongs to the lower socioeconomic class (Social class 4 of Olusanya classification) [14]. MII sleeps in a poorly ventilated room with two adults and has no known history of contact with an adult with chronic cough.
General physical examination on admission showed an ill looking, small for age child, moderately pale, febrile $\left(37.5^{\circ} \mathrm{C}\right)$ with firm, discrete, non-tender submandibular lymphadenopathy measuring less than two centimetre. She weighed $12 \mathrm{~kg}$ (weight for age Z- score of -3SD: weight for height z-score of -2SD), was $98 \mathrm{~cm}$ tall (height for age z-score of -2SD), had an occipito-frontal circumference of $50 \mathrm{~cm}$ and a mid-upper arm circumference of $13 \mathrm{~cm}$. She had a respiratory rate (RR) of 30 breaths/min, a Pulse rate (PR) of 120 beats/ $\mathrm{min}$ and a blood pressure of $80 / 50 \mathrm{mmHg}$.

Her oral mucosa was moist and she had a fair oral hygiene. She had a distended abdomen which moved with respiration with no visible abdominal wall vessel. Ascites was demonstrable by shifting dullness. She had a non-tender hepatomegaly that was palpably enlarged six centimetre below the right costal margin. Her spleen was not palpably enlarged but she had an ill-defined, slightly tender mass extending from the right lumbar to the right iliac region. Her bowel sounds were present and normal. Other systemic examinations were essentially normal.

An initial diagnosis of chronic malnutrition with sepsis to rule out typhoid enteritis was considered. The child was commenced on intravenous (IV) ceftriaxone, genticin and metronidazole, which she received for a total of one week. The symptoms abated and child was discharged home.

One week after discharge the child presented with similar symptoms with signs of moderate dehydration. Abdominal examination done revealed a doughy abdomen with a non-tender hapatomegaly and an ill-defined tubular, slightly tender mass in the right lumbar to right iliac region and markedly increased bowel sounds. A digital rectal examination revealed an empty rectum with the examining finger stained with faecal matter. A diagnosis of partial intestinal obstruction secondary to appendiceal mass was made. She was placed on nil per oris with a nasogastric tube in situ to drain the stomach and the paediatric surgeons were invited to review. She was commenced on IV fluids 5\% Dextrose in $0.9 \%$ saline and IV ceftazidime which was later changed to IV ciprofloxacin and IV metronidazole when there was no improvement in the child's symptoms.

Investigations carried out showed an initial packed cell volume (PCV) of $20 \%$ and child was transfused with a unit of blood. A repeat full blood count (FBC) revealed a PCV of $25 \%$, total white blood cell count (WBC) of $7.4 \times 109 / 1$. a neutrophil count of 37\%, Lymphocyte of 385 , monocyte of $23 \%$, eosinophil of $1 \%$ and basophil of $1 \%$. The platelet count was $466 \times 109 /$ l. the blood film showed hypochromasia, microcytosis, anisocytosis, moderate monocytosis and thrombocytosis. The erythrocyte sedimentation rate (ESR) 
was $111 \mathrm{~mm} / \mathrm{hr}$. The manteoux test was $18 \mathrm{~mm}$. Her Chest Xray was normal. Her plain abdominal x-ray showed abdominal distension and bilateral flank fullness with normal bowel gas distension and no pelvic gas shadow. An impression of ? Partial intestinal obstruction was made. An abdominopelvic Ultrasound scan (USS) revealed a distended ascending colon with thick walls, no peristalsis from caecum to hepatic flexure other bowel loops were normal. An impression of colitis? type was made. Abdominal computed tomography was not done due to financial constraints as all medical expenses are paid out of the patient's pocket. Mycobacterium was not detected in the genexpert of gastric aspirate. Her HIV serology was negative and her haemoglobin genotype was AA. No parasite, ova or organisms were isolated from her stool analysis. Her malaria parasite test was negative and her electrolytes were normal apart from bicarbonate which was $17 \mathrm{mmol}$ initially and this was corrected to $22 \mathrm{mmol}$.

After one week on admission with conservative management, fever, abdominal pain and the abdominal mass still persisted and the child was taken to theatre for an exploratory laparotomy.

The intraoperative findings were: Multiple caseation on the distal ileum, caecum and adjoining mesentery with a partially occluded caecal and ileal lumen and multiple mesenteric lymph node enlargement with a viable gut. The mesenteric lymph nodes were harvested for histopathological examination. No gut resection was made. The histology report revealed features consistent with granulomatous inflammation most likely tuberculous lymphadenitis. Neither genexpert nor TB culture was done on the mesenteric lymoh nodes. Our diagnosis was then reviewed to partial intestinal obstruction secondary to Ileocaecal tuberculosis.

Based on her clinical features, the results of other diagnostic test for TB, a TB score of 7 [15] and the histology report she was commenced on antibtuberculous regimen: an intensive phase comprising of rifampicin, isoniazde, pyrazinamide and ethambutol (RHZE) for two months and a continuation phase comprising of rifampicin and isoniazid (RH) for four months. She improved rapidly after commencement of anti TB medication and all symptoms resolved within a week. The mass had regressed completely and she had gained weight and was weighing $13.5 \mathrm{~kg}$ on discharge. She was discharged home on the 10th day of anti TB medications after five weeks on admission. She was being followed up in the Directly Observed therapy short course (DOTs) unit on outpatient basis. She had since completed her anti- Tb medication and is doing very well.

\section{Discussion}

Our index patient fits into the typical patient with abdominal TB who is usually above 5 years, malnourished and of a low socioeconomic background [16]. The insidious onset and diversity of her symptoms and chronic course of her disease contributed to the initial delay in making a diagnosis and this is not an uncommon finding in abdominal TB $[17,18]$. Our patient presented with constitutional symptoms; fever, weight loss, vomiting, abdominal pain, anorexia, weakness and these has been reported to occur in 50 $60 \%$ of Indian patients with abdominal TB [19]. The finding of an abdominal mass which was present in the right lumbar and iliac region present in our patient has been reported to occur in 19 - 23\% of cases and is said to consists of variable portions of the terminal ileum, caecum and lymphnodes [11]; a finding that was observed in our patient on exploratory laparotomy. Our patient presented with attacks of subacute intestinal obstruction which appeared to resolve initially on conservative management. This presentation has been reported as the classical presentation of the plastic form of TB abdomen [20]. However with the presence of lymphnode enlargement and minimal ascites in our patient there was an overlap and no clear clinical distinction would be made and this feature has also been observed in earlier studies $[4,21]$. Our patient presented with ileocaecal TB which has been reported as the commonest site of enteric tuberculosis. The reason adduced for this is the abundance of lymphoid tissue, physiological stasis and high absorption rate in this region [19].

In our index patient mycobacterium was not detected in gastric aspirate. This poor yield of microbiological proof in abdominal TB due to is paucibacilliary nature [19]. The characteristic caseation of the TB granuloma seen in our index patient has been recognised as a histological marker for abdominal $\mathrm{Tb}$ and helps in its differentiation from Crohn's disease $[22,23]$. It has therefore been recommended that in endemic areas the characteristic histologic features in the presence of suggestive clinical features is sufficient to start treatment. However, it should be noted that a good host defense response or low organism virulence can result in a non caseating granuloma [19,22]. The finding of anaemia and a raised ESR observed in our patient has also been observed in a previous study [20]. Our patient had a raised manteoux of $18 \mathrm{~mm}$, which is in keeping with previous studies that observed raised manteoux in 53.8$57.6 \%$ of cases in their series $[20,24]$. Our patient had a normal chest $\mathrm{x}$-ray, which is not surprising as only $15 \%$ of children with abdominal TB show signs of active TB on Chest X-ray [23]. Our patient's plain abdominal $x$-ray was not suggestive of abdominal TB as it lacked the pathognomic mottled calcification in the mesenteric lymph nodes. However, the thickened descending colon walls seen in our patient has been reported as one of the early sonographic 
features of abdominal TB $[19,25]$. Our diagnosis of Abdominal TB in our patient was established on the basis of histological evidence of a caseating granuloma, operative evidence of $\mathrm{Tb}$, and good response to chemotherapy without subsequent recurrence in a patient with clinical features suggestive of TB. These criteria are among the documented criteria for establishing the diagnosis of Abdominal TB [26]. The presence of intestinal obstruction in our patient and the need for tissue diagnosis necessitated the exploratory laparotomy carried out in our patient. These two conditions are recognised indications for the surgical management of abdominal TB $[3,27]$. Local resection was however not done as the gut tissues were still viable and reports have shown that greater than $90 \%$ of patients with abdominal TB will respond to medical therapy alone if started early enough $[28,29]$. Surgical management of abdominal TB must be carried out with caution to minimize complications like enterocutaneous fistula and it is best to avoid emergency surgery for intestinal obstruction due to abdominal TB as it carries a high mortality $[3,30]$. The aforementioned reasons accounted for our initial use of conservative management and apparent delay in instituting surgical management. Our use of RHZE for the initial two months intensive phase and RH for the following four months continuation phase is in line with the Nigerian national policy for the treatment of abdominal TB [14]. The efficacy of these combination therapy has been attested to by earlier reports [28,31] and it was also observed in our index patient who improved rapidly after commencement of anti-tuberculous medication.

In conclusion, abdominal TB is still seen in Nigerian children. It may present in with nonspecific features. A high index of suspicion is therefore required to make a diagnosis. It should always be a differential in a child with clinical features suggestive of tuberculosis and intestinal obstruction in endemic areas. Attempts should always be made to establish a histologic and microbiological diagnosis. Anti- TB medication is the first choice of therapy and surgery should be reserved for making a diagnosis or treating complications.

\section{Bibliography}

1. Organisation WH. "Global tuberculosis report". Geneva, World Health Organisation. (2016): 214.

2. Wallgren A. "The time-table of tuberculosis". Tubercle 29.11 (1948): 245-251.

3. Bhansali SK. "Abdominal tuberculosis Experiences with 300 cases". The American Journal of Gastroenterology 67 (1977): 324-337.

4. Marshal JBB. "Tuberculosis of the gastrointestinal tract and peritoneum". The American Journal of Gastroenterology 88 (1993): 989-999.
5. Oloyede IP., et al. "Pattern of diagnosis and treatment of childhood tuberculosis in a Teaching Hospital in Southern Nigeria". W J Biomedical Research 6 (2019): 29-38.

6. Vaidya MG and Sodhi JS. "Gastrointestinal tract tuberculosis: a study of 102 cases including 55 hemicolectomies". Clinical Radiology 29 (1978): 189-195.

7. Parthasarthy A., et al. "Controversies in tuberculosis". The Indian Journal of Pediatrics 54 (1987): 779-784.

8. Narasimharao KL., et al. "Abdominal tuberculosis in children". Annals of Surgery 1 (1984): 22-24.

9. Chuttani HK. "Intestinal tuberculosis". in: Card WI, Creamer B (Eds). Modern trends in gastroenterology. London, Butterworths (1970): 308-327.

10. Veeragandham RS., et al. "Abdominal tuberculosis in children: review of 26 cases". Journal of Pediatric Surgery 31 (1996): 170-175.

11. Mukhopadhyay A., et al. "Abdominal Tuberculosis with an Acute Abdomen: Our Clinical Experience". Journal of Clinical and Diagnostic Research 8.7 (2014): NC07-NC09.

12. Burke KA., et al. "Diagnosing abdominal tuberculosis in the acute abdomen". International Journal of Surgery 12 (2014): 494-499.

13. Bhansali SK and Sethna JR. "Intestinal Obstruction: A clinical analysis of 348 casas". Indian Journal of Surgery 32 (1970): 5770.

14. Olusanya 0., et al. "The importance of socioeconomic class in voluntary fertility control in a developing country". West African Journal of Medicine 4 (1985): 205-212.

15. Adamu I., et al. "National Tuberculosis and Leprosy Control Programme: Workers' manual $5^{\text {th }}$ edition". Abuja: FMOH (2008).

16. Sherman SS., et al. "Tubercular enteritis and peritonitis". Archives of Internal Medicine 140 (1980): 506-508.

17. Boukthir S., et al. "Abdominal tuberculosis in children. Report of 10 cases". Acta Gastro-Enterologica Belgica 67 (2004): 245249.

18. Hadad FS., et al. "Abdominal tuberculosis". Dis Colon Rectum 30 (1987): 724-735.

19. Bajpai M and Gupta DK. "Abdominal tuberculosis in Seth V, Kabra SK (Eds). Essentials of tuberculosis in children". New Delhi, Jaypee brothers (2006): 143-156. 
20. Thapa BR., et al. "Abdominal tuberculosis". Indian Pediatrics 28 (1991): 1093-1100.

21. Tendon RK., et al. "A clinic radiological reappraisal of intestinal tuberculosis". Journal of Gastroenterology 21 (1986): 17-22.

22. Tandon H. "The pathology of intestinal tuberculosis". Tropical Gastroenterology 2 (1981): 77-93.

23. Kapoor VK. “Koch's or Crohn's". International Journal of Clinical Practice 51 (1997): 246-247.

24. Manohar A., et al. "Symoptoms and investigative findings in 145 patients with tuberculous peritonitis diagnosed by peritoneoscopy and biopsy over a fdive year period". Gut 31 (1990): 1130-1132.

25. Jain R., et al. "Diagnosis of abdominal tuberculosis, sonographic findings in patients with early disease". American Journal of Roentgenology 165 (1995): 1391-1395.

26. Marks IN. "Abdominal tuberculosis". In: Watters DAK, (Ed). Bailliere's clinical, tropical and communicable disease, London Balliere (1998): 329-348.

27. Ahmed ME and Hassan MA. "Abdominal Tuberculosis". Annals of the Royal College of Surgeons of England 76 (1994): 75-79.

28. Biddulph J., et al. "Short course chemotherapy in childhood tuberculosis". Journal of Tropical Pediatrics 34 (1988): 20-23.

29. Millar AJW., et al. "Abdominal tuberculosis in children - Surgical management: a 10 year review of cases". Pediatric Surgery International 5 (1990): 392-396.

30. Lingenfalsen T., et al. "Abdominal Tuberculosis: Still a potentially lethal disease". The American Journal of Gastroenterology 88 (1993): 744 -750.

31. Cohn DL., et al. "A 62 - dose, 6 months therapy for pulmonary and extrapulmonary tuberculosis: A twice weekly, directly observed and cost effective regimen". Annals of Internal Medicine 112 (1990): 407-415.

\section{Assets from publication with us}

- Prompt Acknowledgement after receiving the article

- Thorough Double blinded peer review

- Rapid Publication

- Issue of Publication Certificate

- High visibility of your Published work

Website: www.actascientific.com/

Submit Article: www.actascientific.com/submission.php

Email us: editor@actascientific.com

Contact us: +919182824667 